\title{
CASTRIL: DE ḤIȘN FRONTERO A SEÑORÍO BAJOMEDIEVAL
}

\author{
Concha ALFARO BAENA \\ Universidad de Granada
}

Los estudios referidos a la tierras fronterizas entre el reino nazarí de Granada y la corona de Castilla son muy numerosos, y prácticamente han abarcado todos sus sectores. Las más modernas corrientes investigadoras introducen en esta temática nuevos análisis de la problemática social y económica de estos territorios, que vienen a completar el ya tradicional punto de vista político. $Y$ es que, realmente, la frontera es algo más que guerras y treguas, cabalgadas, cautiverios y rescates, conquistas y reconquistas.

Es indudable que para llevar a cabo esta labor también ha sido necesaria la utilización de nuevas fuentes de conocimiento. La documentación escrita, tanto cristiana como musulmana, ha proporcionado la mayor parte de las noticias que hasta hoy se conocen de este complejo mundo que es la frontera. Pero los esperanzadores resultados que la arqueología está proporcionando para el estudio de lo que fue el reino nazarí de Granada, y sobre todo para el mundo rural ${ }^{1}$, nos obligan a su aplicación en los estudios fronterizos. Sirva como ejemplo, los importantes sistemas defensivos con que cuenta, que apenas han sido objeto de estudio por parte de los Historiadores del Arte; o del gran número de despoblados originados por los avances y retrocesos de la línea y su consiguiente inestabilidad, cuyo estudio se hace hoy en día imprescindible.

Proponemos aquí el análisis de un pequeño territorio que pasó a formar parte de la frontera granadino-jiennense desde principios del siglo XIII: el Ḥișn Qastāl. Para ello hemos utilizado la importante colección documental referida a esta zona, dada a

1 Al respecto merecen especial mención los trabajos que se han llevado a cabo por el profesor Antonio Malpica Cuello en la costa de Granada, el profesor Tomás Quesada Quesada en el sector fronterizo de Sierra Mágina y la profesora Carmen Trillo San José en la Alpujarra granadina. 
conocer y estudiada por el profesor Juan de Mata Carriazo y Arroquia. Otra parte importante de los documentos consultados proceden del Archivo General de Simancas, especialmente el Repartimiento de $1527^{2}$, que proporciona importantes datos para el período posterior a la conquista cristiana. Incluimos también las aportaciones que hasta este momento hemos obtenido de las fuentes arqueológicas.

Castril (Qastã) se localiza en el extremo nororiental de la provincia granadina en las estribaciones montañosas de la Sierra de Cazorla que en esta zona es conocida como Sierra de Castril. Alcanza altitudes de hasta $2.000 \mathrm{~m}$, si bien en dirección S se suaviza hasta los $900 \mathrm{mts}$. La vegetación dominante corresponde a la especie Quercus, sobre todo encinas, que en las zonas más húmedas deja paso al quejigo. Las áreas más altas de la sierra se encuentran pobladas de un bosque de coníferas con especies tales como el pino laricio y un denso matorral de tipo mediterráneo. Cuenta también con importantes pastizales de alta montaña en cotas superiores a los 1.500-1.700 $\mathrm{m}$, que presentan la enorme ventaja de poder ser aprovechados una vez que han desaparecido las nieves, es decir a partir de mayo o junio, cuando ya están prácticamente agotados los de las zonas más bajas. Esto dió lugar, al menos desde época medieval, a una importante corriente trashumante a través del puerto de Tíscar $^{3}$. La existencia de un curso permanente de agua, el río Castril (Wādî-l-Qastā $\bar{l}$ ), bien canalizado y aprovechado a través de una compleja red de acequias, molinos y albercas ha permitido el riego de extensas zonas de tierra y por consiguiente el establecimiento de una importante agricultura de regadío y de huerta que convivía con la de secano.

La frontera oriental del Reino de Granada quedó definida en el sector que nosotros estudiamos desde principios del siglo XIII, coincidiendo con el avance de Fernando III por tierras jienenses y murcianas. En 1231 el monarca hizo donación al arzobispo de Toledo D. Rodrigo Jiménez de Rada un amplio territorio que tenía como área de expansión las hoyas de Guadix y Baza ${ }^{4}$. Para ello pronto los cristianos se hicieron con todos los castillos de la cabecera del río Guadiana Menor - Cuenca, Chiellas, Torres de Alicún, Cebas, Cuevas de Almizdra y Cúllar--, entrada natural desde el Guadalquivir hacia estas tierras. En el sector murciano ocurre algo similar, ya que en 1243 pasa también a poder cristiano junto con el resto del Reino. Un año antes la Orden de Santiago había recibido de Fernando III Segura de la Sierra, siguiendo la misma política que con el Adelantamiento de Cazorla. De esta manera a la vez que era premiada por sus acciones militares permitía el establecimiento de una base fuerte que hiciese frente a los granadinos en su intento de apoderarse del reino murciano. Los

2 Este documento fue el objeto de nuestra Memoria de Licenciatura, en la actualidad en prensa.

3 Antonio MALPICA CUELLO, «Fiscalidad y comercio de la sal en el reino de Granada en la Edad Media», Das Salz in der Rechtsund Handelsgeschichte. Internationaler Salzgeschichtekongres, 1990, pp. 65 94.

4 "Que él(el arzobispo de Toledo) había rogado y suplicado humildemente que no se anulase en sus días la antigua autoridad de loas arzobispos de Toledo, a todos los cuales se había permitido atacar hasta recuperarlas las dos ciudades de Baza y Guadix...". Alonso de PALENCIA, Crónica de Enrique N, trad. A. PAZ Y MELIA. B.A.E. CCLVII-CCLIX, Madrid, 1973-1975, p. 103. 
santiaguistas que ya ocupaban Huéscar se hacen con Galera, Orce y Castilléjar, que les son donados por privilegio real de 1243.

Salvo en determinados momentos en que cristianos y musulmanes alcanzan alguna paz estable los enfrentamientos fronterizos marcan la actividad de esta zona durante los dos siglos siguientes. De esta manera el área bastetana no conoció descanso alguno, manteniendo un estado de alerta permanente que llevó al establecimiento de uno de los más importantes sistemas defensivos de todo el reino.

Las primeras noticias que tenemos de Castril se refieren a Lezas. Se trata de un despoblado de época musulmana localizado en el pago de mismo nombre en el tramo alto del río Castril ${ }^{5}$. Situado a media ladera y en la margen derecha del río presenta fácil acceso desde éste. Está en una zona muy fértil, rodeada de pastos y donde aún hoy es posible distinguir restos de abancalamientos y terrazas de cultivo. En el siglo $\mathrm{XVI}$ contaba este lugar con el aporte del agua proveniente de un arroyo Royo de Lezas, que hoy se encuentra seco ${ }^{6}$. No son visibles, en cambio, estructuras de muros, salvo algunas canalizaciones de agua y en el perfil de un corte de sembrado han aparecido restos de enterramientos cubiertos en su parte superior por unas lajas de piedra. A pesar del grado de destrucción que presentan y de la necesidad de proceder a su excavación y estudio, no descartamos que sean de época árabe. La cerámica procedente de este yacimiento ha proporcionado restos de sigillata que permiten apuntar la presencia romana en éste área y ponerla en relación con otros yacimientos aparecidos en el curso del río Castril?. En su mayor parte, la cerámica arroja una cronología en torno a los siglos XI y XII. No existe ningún fragmento susceptible de ser datado con posterioridad y es escasa la presencia de cerámica a mano que permita establecer una datación anterior.

A propósito de este lugar tenemos constancia del topónimo Lezar en una donación que en 1294 hace Sancho IV a don Gonzalo García Gudiel y posteriormente, en 1384, en una sentencia por el pleito que mantenían Ubeda y la mitra de Toledo sobre los lugares de Quesada y sus límites con Cazorla. En ella aparece citada como una aldea:

"e dende a las aldeas de la dicha villa, quales son leçar, çebas, que parten con Castril, lugar del rei de Granada»".

Parece clara, por tanto, la correspondencia entre yacimiento y topónimo dado su proximidad a Cebas y Castril, junto a las que aparece citada en la fuentes, y la no

5 M.I.G.N., hoja 929 , San Clemente, 1:50.000, $0^{\circ} 54^{\prime}-0^{\circ} 55^{\prime} / 37^{\circ} 51^{\prime}-37^{\circ} 50^{\prime}$

6 "Primeramente una haça en el Leças que es del camino arriba, que tiene seys hanegas sacadas, que es linde de Alcotroy y del royo de Leças y con el rio". A.G.S.-G.A., leg. 1315, fols. 145, 146 y 227.

7 Milagros SOLER CERVANTES, “Proyecto de estudio de poblamiento en la prehistoria reciente en la Depresión de Baza-Huéscar», Campaña de Prospección de 1991, Investigaciones Arqueológicas en Andalucia, 1985-1992, Huelva, 1993, pp. 815-821.

8 Juan de Mata CARRIAZOY ARROQUIA, Colección Diplomática de Quesada, Jaén, 1975, Doc. núm. 31, pp. 57-66. 
existencia en todo el área de algún topónimo similar. Los restos del despoblado medieval existentes en este pago nos llevan a confirmar que era éste el lugar donado a don Gonzalo García Gudiel. Por último en el reparto de tierras que se hace en 1527 al objeto de animar la repoblación de la zona, se entregaron en este pago un total de treinta y cinco fanegas y media a cuatro vecinos, de las que únicamente una y media correspondían a monte y por tanto estaban pendientes de roturar.

Más temprana es la cronología que nos ofrece el hișn Qastāl, donde han aparecido algunos fragmentos pertenecientes al período emiral. No obstante, el grueso de la cerámica de este yacimiento se data en los siglos XII a XVI, coincidiendo con las noticias que nos ofrecen las fuentes escritas. El castillo se ubica en un espolón rocoso - conocido como las Peñas $-{ }^{9}$ en la margen izquierda del río dominando todo su valle. Este lugar ha sido objeto del sistemático expolio de furtivos que en varias ocasiones han procedido a realizar excavaciones dentro del recinto, a lo que debemos añadir la presencia de algunas construcciones modernas que han acelerado su destrucción. A pesar de ello es posible distinguir algunos de sus elementos más significativos. De planta irregular tiende hacia un rectángulo y sobre una base de materiales calizos se pueden observar restos de muros de mampostería en el extremo $\mathrm{N}$ y SE, donde además se encuentra una torre y otra que emerge. En la zona $S$ se encuentran los restos de dos aljibes, uno dentro de otro, que aún presentan restos de enlucido. No se han podido contabilizar el número de torres con que contaría la fortaleza pero debió ser elevado ${ }^{10}$.

La única descripción con que contamos de esta fortaleza la realizó en el s. XII alZurhi, en los siguientes términos:

"A poniente de este monte sale el río llamado Guadiana [Menor], que baja hacia la fortaleza llamada Castril (Qastâl). En el patio de dicha fortaleza se encuentra la gran piedra de la que mana agua y que es una piedra lisa que se alza enormemente sobre el suelo. En su parte superior hay una fuente de la que brota tal cantidad de agua que podría mover ocho piedras [de molino]. En el estanque [que se forma] existen muchos peces de color amarillo con lunares rojo, que poseen dientes caninos y molares. Ni en el mar ni en los ríos existen peces más finos que éstos. Quien los contempla correteando entre las cavidades de las rocas se imagina que son espadas [centelleantes] o destellos de relámpago. Luego el agua se esparce entre los peñascos y desciende hasta el Guadiana [Menor] hasta que se junta con el Guadalquivir»"1.

Este castillo hay que ponerlo en relación con el sistema defensivo de la zona oriental del reino. En concreto formaría parte de un tercer cinturón en torno madīnaţ Basţa y por su condición fronteriza desarrollaría una importante labor de vigilancia y defensa

9 "Yten un colmenar que esta baxo de las Peñas de la fortaleza". A.G.S.-R.G.S., leg. 1315, fols. 145,146 y 227.

10 Antonio MALPICA CUELLO, Poblamiento y Castillos en Granada. Barcelona, 1996.

11 Dolores BRAMONS, EI mundo en el siglo XII. Estudio de la versión castellana y del original árabe de un geografía universal, «El tratado de al-Zuhrī», Barcelona, 1991, p. 173. 
de los pasos que a través de la sierra comunicaban tierras cristianas y musulmanas. A su vez se encontraba en contacto visual con las atalayas que salpicaban el territorio y que conectaban con Baza. Sabemos que para su mantenimiento contaba con un habiz consistente en un aljibe y un inmueble en las inmediaciones de la ciudad de Baza. La cuarta parte del usufructo que se obtenía de estos bienes eran destinados al hișn Qastāl que compartía esta renta con los caballeros pobres de Baza, los estudiantes de esta ciudad más necesitados y el propio administrador del habiz que recibía otra cuarta parte ${ }^{12}$.

Un núcleo habitado se asentaba en las laderas de este prominente rocoso, formado por un grupo de casas que disponían de su propia muralla ${ }^{13}$. Así pues nos encontramos con lo que los cronistas cristianos denominan villa fronteriza, ubicada en un lugar elevado dominando el valle del río y protegida por su propia muralla, dentro de la cual y en lugar destacado se encontraba la fortaleza que contaba también con su propio muro defensivo. A ella acudiría a refugiarse la población en caso de peligro.

En cuanto a las casas sabemos por el texto de 1527 que algunos de los nuevos pobladores procedieron a la construcción de sus propias moradas en este momento, lo cual nos induce a pensar que o bien la población musulmana que habitaba el lugar anteriormente fuese sensiblemente menor, o bien que las casas que se habían conservado, por sus peculiares características, no fuesen del agrado y la comodidad de los recién llegados. Estos decidirian bien hacerse una nueva, bien adaptar las que les fueron entregadas.

Otro de los lugares que encontramos en fecha temprana en la documentación cristiana es Cebas. Aparece citado en diversas ocasiones como uno de los castillos de la cabecera del Guadiana Menor que en 1245 estaban en poder de los cristianos ${ }^{14}$, en otros casos se le da el calificativo de aldea ${ }^{15}$. Nosotros no hemos podido confirmar la existencia de una fortaleza en el paraje que con este nombre se encuentra en las inmediaciones de Castril. Efectivamente, a unos 5 kilómetros al $\mathrm{O}$ de esta población y en la margen derecha del río se localiza el pago conocido como Campo Cebas ${ }^{16}$. Una parte importante de este terreno participa del relieve montañoso de la Sierra de Castril, donde hasta principios del siglo XVI el bosque debió ocupar una parte destacada de su superficie. Conforme desciende hacia el río se suaviza la pendiente dando lugar a una extensa llanura apta para los cultivos de secano.

Tradicionalmente Cebas ha sido lugar de frontera y paso hacia la vertiente $\mathrm{N}$ de la

12 Vicent LAGARDÈRE, Campagnes et paysans d'Al-Andalus (VII/ -XVe S.), Paris, 1993, p. 281.

13 "Yten vna casa que alinda con la de Juan Abad y con Diego Amador y el adarue de la villa". A.G.S.-G.A., leg. 1315, fols. 145, 146 y 227.

14 Juan de Mata CARRIAZO Y ARROQUIA, Colección Diplomática de Quesada..., Doc. núm. 8, p. 11.

15 Archivo de la Real Chancillería de Granada, cab. 506, leg. 1106, pieza 3. Pleito del Concejo de Cazorla con Fernando de Zafra sobre la mojonera de los términos de Castril.

16 «Que el campo de Cebas es una llanura situada al pie de la sierra de Castril, poblado de cortijos y, las tierras que no se labran, de monte". Tomás LÓPEZ, Diccionario geográfico de Andalucía: Granada. Ed. Cristina SEGURA GRAIÑNO y Juan Carlos DE MIGUEL, Granada, 1990, p. 53. 
Sierra de Castril con la que mantiene fácil comunicación a través del camino, que cruzándola, llega al núcleo de Los Almiceranes. Pero también el camino Real de Pozo Alcón a Castril, que no pasa por lo que hoy es el núcleo de los cortijos, sí lo hace por lo que se conoce como el Campo, al $\mathrm{S}$ de Cebas.

Su cercanía a Quesada hicieron de esta zona lugar de influencia del Adelantamiento de Cazorla, siendo de hecho la frontera por excelencia. En la delimitación de términos que se hizo en 1384 entre los lugares de Quesada y Cazorla, el Adelantamiento tenía su límite hacia el SE en «la enzina santa questa entre Cebas e Castril»17, esta última perteneciente al rey de Granada. La tan próxima presencia de los granadinos debió ser un obstáculo que impidiera a Cazorla el uso y aprovechamiento de estos términos hasta que la fortaleza de Castril pasase a poder cristiano. Sin embargo Fernando de Zafra, nuevo señor de Castril desde 1490, defendió sus derechos sobre estos territorios y consiguió este mismo año la confirmación de una sentencia que reconocía la pertenencia de estos términos a Castril desde tiempo inmemorial ${ }^{18}$. Lo que estaba en cuestión era una importante zona de pastos a la que tradicionalmente acudían los pastores de Ubeda y a la que no estaban dispuestos a renunciar, según se desprende de la declaración tomada a los testigos del pleito en 1494:

"Preguntado sy supo del dicho ganado que se traxo de Diego de Baeça, vesino e regidor de Ubeda e que se tomo en el Campo Cevas dixo que lo ha oydo desir publicamente en esta villa. Preguntado sy el dicho Campo Çevas es parte donde se tomo el dicho ganado del dicho Diego de Baeça sy es mas adentro hasia Castril de los dichos mojones que declaro querian los moros de Baça e Castril segund derechos, dixo que el dicho Campo Çevas es en medio poco mas o menos de entre los dichos mojones querian los dicho moros por suyos... e que sabe que quando yvan a dar los dichos rastros a los dichos moros e los tomavan no los queryan reçibir salvo por los dichos mojones que ellos desian" "19.

Desde este momento se inició el que es conocido como pleito de La Marmota que duró unos cinco años y que puede ser considerado como uno de los más interesantes conflictos de términos en el oriente granadino tras la llegada de los cristianos.

17 Juan de Mata CARRIAZO Y ARROQUIA, Colección Diplomática de Quesada..., Doc. núm. 31 , pp. $57-66$.

18 «... fallaramos que la dicha villa de Castril y su procurador, en su nombre propio conplidamente su yntençion conviene a saber los terminos que la dicha demanda contenidos averlos poseydo de tiempo ynmemorial a esta parte el conçejo, alcayde e vesinos de la dicha villa de Castril, asy en los tiempos que las ayan los moros como despues que fue de xristianos paçificamente usando de los dichos terminos e arrendandolos e llevando los frutos dellos e prendando a los vesinos de la dicha villa de Caçorla cada e quando en los dichos terminos entrauan». A.G.S.-R.G.S., VII-1490, fol. 311.

19 A.R.Ch.Gr., cab. 506, leg. 1106, pieza 3. Pleito del Concejo de Cazorla con Fernando de Zafra sobre la mojonera de los términos de Castril. 


\section{LA FORMACIÓN DEL SEÑORÍO DE CASTRIL}

Tras la campaña de 1488 la mayor parte de la alquerías de la hoya de Baza habían pasado a poder de los cristianos, situándose la frontera, prácticamente en la misma vega de la ciudad. Así pues, era lógico que el próximo objetivo fuese Baza, ya que si finalmente esta ciudad era ganada se rendirían el resto de las grandes ciudades de la zona oriental que permanecían fieles a El Zagal, Almería y Guadix, y por tanto se completaría la ocupación de todo este territorio del reino granadino ${ }^{20}$.

En mayo de 1489 se inician las operaciones militares desde Jaén, tomando el camino hacia Quesada y Tíscar, para entrar en la hoya de Baza a través del curso del río Guadiana Menor. Instalado el real en Sotogordo, una parte de los contingentes se dirigieron hacia el Campo Cuenca, en las inmediaciones de Castril, desde donde entraron en la fortaleza que fue la primera de toda la zona en rendirse ${ }^{21}$. A principios de diciembre Baza capituló después de un penoso asedio de seis meses.

Las primeras noticias que disponemos de Castril, ya en manos cristianas, datan de 1490 y nos señalan que el lugar quedó despoblado como consecuencia de la guerra:

"Castril quando era poblada dizen que valia hasta çiento fanegas de pan de renta e que tiene muy buena sierra que abran en ella cada un año veynte mill cabeças de ganado que pagaran de doze vna que son dozientas $e$ quarenta cabeças, agora por la pas valdra mas»²2.

No obstante, parece seguro que permaneció un pequeño grupo de población mudéjar dedicado a la ganadería, actividad ésta que no requiere una importante fuerza de trabajo. Sin embargo si pudo haber un abandono por parte de aquellas personas que vivían de la agricultura.

Castril fue pronto enajenada a favor del secretario real, Fernando de Zafra, quien por merced la recibió por juro de heredad el 16 de febrero de 1490 como pago a «los muchos e buenos e señalados e leales serviçios... que nos avedes fecho e fazedes cada dia, espeçialmente en la guerra de los moros... „»23. Se trataba de una concesión peculiar que nos impide hablar de un «señorío pleno», ya que no le fueron reconoci-

20 "Especialmente determinaron de poner sitio sobre la cibdad de Baza; porque fue platicado en su consejo, que si aquella cibdad se ganase, seria menos trabajosa la conquista de las cibdades é castillos que en aquellas partes quedaban por conquistar». Hernando DEL PULGAR, Crónica de los muy altos e poderosos Don Fernando é Doña Isabel rey e reyna de Castilla é de Leon é de Sicilia, Ed. Cayetano Rosell, Crónica de los Reyes de Castilla, III, B.A.E., LXX, Madrid, 153, p. 481.

21 Juan de Mata CARRIAZO Y ARROQUIA, "Los relieves de la Guerra de Granada en el Coro de Toledo", En la frontera de Granada. Homenaje al profesor Carriazo, vol. l, p. 362.

22 A.G.S.-Diversos de Castilla, leg. 44, p. 24.

23 A.G.S.-R.G.S., $11-1490$, fol. 25. 
dos ni la facultad de juzgar ni la potestad sobre los moradores ${ }^{24}$. Únicamente se especificaba la posesión militar de la fortaleza y del dominio territorial e incluso cuando en muchos casos es la Corona la que se quedaba para sí el control de las fuentes de riqueza, en este caso es el secretario Zafra quiene tiene el domino absoluto de "todo ello desde la hoja del monte hasta la piedra del río "25. El 13 de septiembre de ese año concedía Carta-Puebla a los pobladores y moradores del lugar ${ }^{26}$, en un intento de animar a la repoblación con cristianos viejos.

Que en Castril permaneció un grupo de mudéjares lo confirma la presencia de Abd Allah el Cotrob, musulmán que había ayudado a los cristianos a entrar en este lugar y que ahora es nombrado su alcalde y alguacil, además de recibir importantes propiedades tanto en Castril ${ }^{27}$ como en otros lugares de la hoya de Baza ${ }^{28}$. Pero además el propio texto de la Carta Puebla lo señala:

"No han de criar puercos en las huertas ó lugares de los moros, é si criaren sus haciendas de los dichos moros, puedan matar en pena».

«Ha de quedar el horno para el alfaquí é para la mezquita»"29.

El señor de Castril fijó en doscientos los vecinos que podrían avecindarse y a los cuales entregarían huertas e tierras para pan y viñas, es decir tierras de secano y regadío. Se les permitía construir una casa y además Fernando de Zafra les ayudaba a cada uno con mil maravedíes que debían ser devueltos al cabo de cuatro años. Este plazo se fijaba también para poder vender las tierras que les eran entregadas, siempre a vecinos del mismo lugar y nunca a forasteros. Además se les imponía como única carga durante los primeros cuatro años el diezmo de los frutos que obtuvieran y a partir del quinto año deberían entregar el quinto de todas las cosas de labranza y crianza.

En cuanto a los pastos se distinguían las zonas de llano en las cuales se podía pacer «sin derechos y la sierra con derechos» ${ }^{30}$, lo cual significaba su arrendamiento,

24 En 1502 los reyes le otorgan por merced vitalicia la jurisdicción civil y criminal de esta villa que no se había contemplado en la concesión de 1490. A.G.S.-R.G.S., II-1502, sin foliar, en Enrique PÉREZ BOYERO, «Hernando de Zafra: secretario real, oligarca granadino y señor de vasallos», Miscelánea Medieval Murciana, vol. XVIII (1993-1994), pp. 175-207.

25 A.G.S.-R.G.S., II-1490, fol. 25.

26 Copia de la escritura de transacción otorgada en 10 de noviembre de 1893, entre los actuales dueños de los bienes procedentes del antiguo señorío de la Villa de Castril y hacendados y vecinos de la misma villa. Granada, Imprenta de Vda. e Hijos de P.V. Sabatel, 1895. Agradecemos a D. Vicente González Barberán que nos facilitara esta escritura.

27 A.G.S.-G.A., leg. 1315., fols. 145, 146 y 227.

28 Miguel Ángel LADERO QUESADA, Granada después de la conquista: repobladores y mudéjares. Granada $1993\left(2^{a}\right)$, p. 134.

29 Copia de la escritura de transacción otorgada...

30 Copia de la escritura de transacción otorgada... 


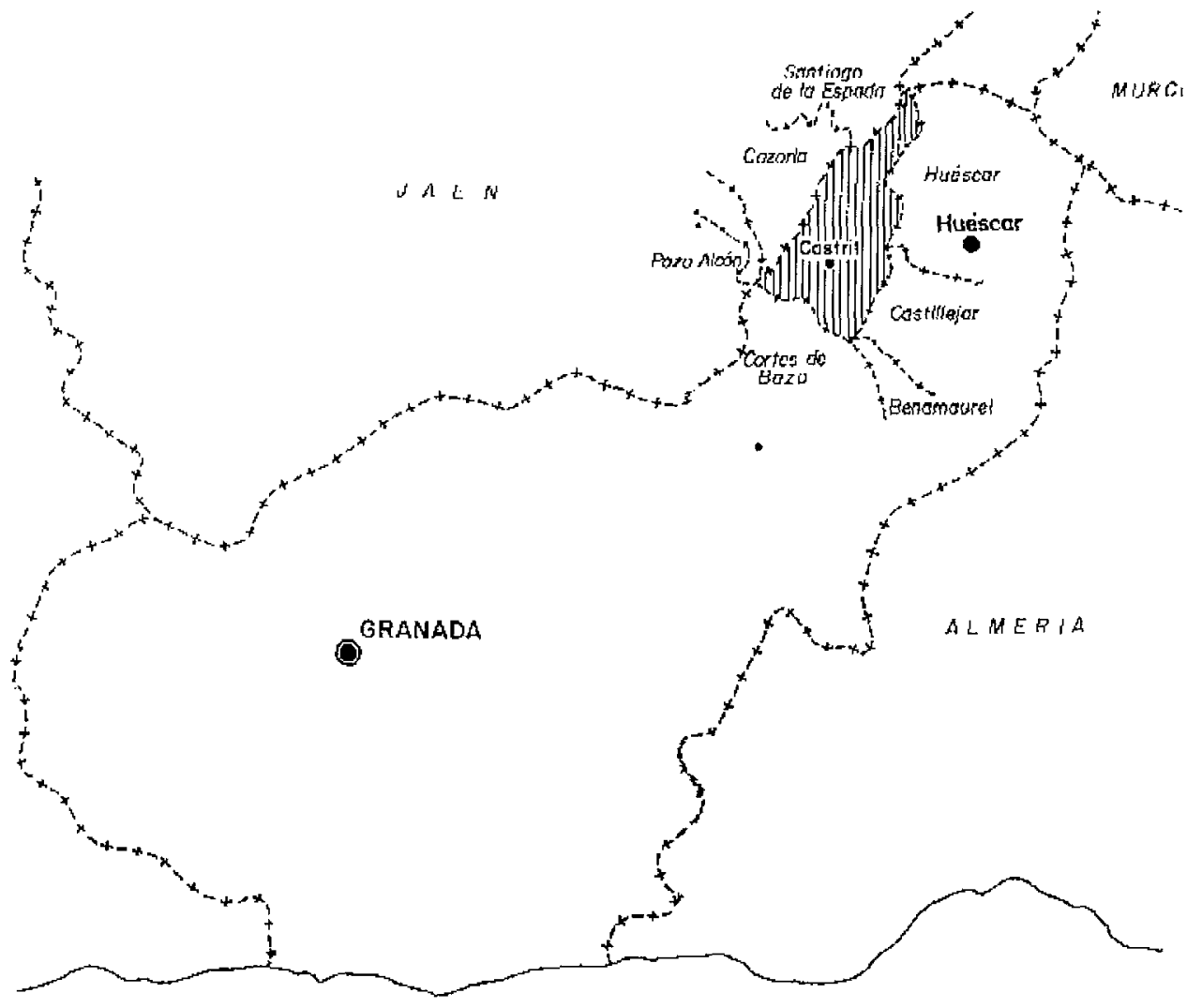

que el secretario real inició pronto, a fin de obtener alguna rentabilidad de sus nuevos dominios $^{31}$. Si bien sabemos que agricultura y ganadería convivían antes de la llegada de los cristianos, y que de esta última se obtenían importantes beneficios, no sabemos si la presión del fisco nazarí llevó a los musulmanes a arrendar sus pastos a los cristianos del otro lado de la frontera como ocurría frecuentemente en las zonas de Málaga $^{32}$ y Jaén ${ }^{33}$. Además esta actividad parece estar estrechamente asociada a la importante explotación salinera existente en torno al río Guadiana Menor, cuya sal sería aprovechada para alimento del ganado ${ }^{34}$.

31 "Sepades que Juan Lopez Çatyco vesino de la çibdad de Huesca nos fizo relaçion disiendo que algunas personas e conçejos deven e son obligados de dar e pagar ciertas quantias de maravedis de la renta y hervajes de los terminos de Castril que el diz que tiene arrendado de Fernando de Çafra nuestro secretario cuya es la dicha Castril». A.G.S.-R.G.S., 1496 II, fol. 30.

32 Manuel ACIÉN ALMANSA, La vida fronteriza en la zona meridional de la Serranía de Ronda (1470-1501), Granada, 1974, (Memoria de Licenciatura, inédita), p. 75.

33 Tomás QUESADA QUESADA, La Serranía de Mágina en la Baja Edad Media. Una tierra fronteriza con el Reino Nazari de Granada. Granada, 1989, p. 262.

34 Antonio MALPICA CUELLO, «Fiscalidad y comercio de la sal...», p. 89. 
No obstante, para llevar a cabo sus planes, Fernando de Zafra debió delimitar los términos de su señorío, tanto hacia el $E$ como hacia el $O$ a raíz de la gran pugna que se desató entre los nuevos señoríos de la hoya de Baza. En 1491 los Reyes Católicos decidieron el mantenimiento de la comunidad de pastos, norma de tradición musulmana que permitía la libre circulación del ganado. Su principal consecuencia fue el inicio de largos pleitos entre estas villas para delimitar los términos que correspondían a cada una de ellas, con la intención velada de impedir que los ganados de los lugares vecinos penetrasen en sus tierras a pastar.

Ya vimos el pleito de La Marmota que consiguió legitimar una sentencia dada en 1384 que incorporaba la importante zona de Cebas al término de Castril. Algo similar ocurrió con la denominada Hoya de la Puerca, actualmente en la provincia de Jaén en los terrenos ocupados por el Embalse de la Bolera, donde se encontraba el paso fronterizo de los dos reinos ${ }^{35}$ y que al menos hasta el siglo XVIII formaba parte del término de Castril ${ }^{36}$.

Para evitar problemas con el Condestable de Navarra, nuevo propietario de Huéscar, en el límite $O$ del término, Zafra solicitó de los Reyes una carta de amparo sobre «terminos e prados e pastos e montes e dehesas e abrebaderos de la villa de Castril fazia la parte de la villa de Huéscar " ${ }^{37}$, según le correspondían desde que estaba en poder de los musulmanes. En cuanto al pleito con Castilléjar, es de fechas posteriores, 1548, y en el se cuestionaba la propiedad de un área de

nominada Campo del Rey, rico también en pastos, que era tenido como suyo por los vecinos de esta villa, pero donde también acudían con frecuencia los hatos de Castril a pacer ${ }^{38}$.

No tenemos noticias de cual fue la respuesta a la Carta-Puebla de 1490 y el alcance que tuvo este primer intento repoblador. Sin embargo contamos con un reparto de tierras llevado a cabo en 1527 por los herederos de Zafra, que afectó a 65 «... veçinos viejos de esta villa de Castril que se entienden los que estan aqui antes del primero dia de henero de $1527, " 39$. Todo parece indicar que se trata de un nuevo Repartimiento, independiente del llevado a cabo en 1490, por el cual los beneficiarios reciben tierras de secano, regadío, casas o en su defecto solares y, majuelos.

Incluye este reparto un conjunto de cláusulas que pretenden ordenar la repoblación e impedir que ésta se convierta en un medio fácil de obtención de ríqueza. De esta manera se obligaba a los vecinos a esperar un mínimo de cinco años para poder

35 "Yten otra aça en la Oya de la Puerca, linderos la mojonera del Campo de Cámara y por la otra parte Juan Garcia y Fernan Lopez, que tiene setenta hanegas sacadas y de ensanche diez hanegas que estan de monte, entre lo labrado y los dichos mojones de Campo de Camara y de esta villa, entiendase que es alinde de ella Aça Grande en el pecho frontero", A.G.S.-R.G.S., G.A., leg. 1315, fols. 145,146 y 227.

36 Tomás LÓPEZ, Diccionario geográfico de Andalucía..., p. 52.

37 A.G.S.-R.G.S., II-1497, fol. 237, en Concepción ALFARO BAENA, La formación de un señorio en el Reino de Granada. El caso de Castril. Granada, 1993. (Memoria de Licenciatura, en prensa).

38 A.R.Ch.Gr., 3/478/11.

39 A.G.S.-G.A., leg. 1315. fol. 146. 
vender las propiedades que le eran entregadas, debían pagar el terrazgo de los frutos que obtuvieran "de cada nueve fanegas una ${ }^{40}$. Para las tierras de monte se establecían condiciones muy específicas de tal manera que quedaba expresamente prohibida su compra o venta si no estaban roturadas.

En cada donación se detallan las fanegas comprendidas en cada lote indicándose la localización del pago y sus límites. También se hace referencia específica a las fanegas que son de monte y que están pendientes de roturar. Se incluye la suma total de las fanegas y las casas y huertas con sus respectivos lindes.

En líneas generales del estudio de este documento se puede concluir que fueron entregadas un total de $2.888,5$ fanegas de tierra en treinta y un pagos distintos, de las cuales $1.604,5$ correspondían a secano, 553,5 a regadío y 730,5 participa de ambos en una proporción que no hemos podido determinar. Las zonas de regadío estan mucho más fragmentadas y sus parcelas serían de un tamaño mucho menor que las de secano, en donde prevalecía una mayor homogeneidad.

Hemos podido constatar la no existencia de grandes disparidadęs, de tal manera que aunque una pequeña minoría se beneficia del reparto, en líneas generales, tanto el tamaño como al calidad de las tierras que reciben son similares.

El total de la superficie roturada y ganada al monte apenas llega al $12 \%$ y se halla repartida en propoción a la extensión de cada pago. No obedece, tanto a su distribución geográfica como a la cantidad que corresponde a cada poblador a una necesidad de aumentar la superficie de cultivo por falta de tierras. Más bien hay que buscar la causa de este hecho en la progresiva adaptación del territorio disponible a aquellos cultivos más propios de la economía castellana. Estas tierras que ahora se incorporan son destinadas en su mayor parte al cultivo de cereales, si bien la presencia de hortalizas, frutales y plantas textiles seguía siendo importante ${ }^{41}$.

En definitiva tenemos que hablar de una nueva reorganización económica de este lugar, que relega a un segundo plano la ganadería en favor de la agricultura, ya que el aumento de la producción agrícola permitía la obtención de mayores beneficios para el señor de la villa.

40 A.G.S.-G.A., leg. 1315, fol. 146.

41 Concepción ALFARO BAENA, La formación de un señorio en el Reino de Granada. El caso de Castril. Granada, 1993. (Memoria de Licenciatura, en prensa). 